\title{
Front Matter: Volume 9500
}

, "Front Matter: Volume 9500," Proc. SPIE 9500, Quantum Information and Computation XIII, 950001 (19 June 2015); doi: 10.1117/12.2201029

SPIE Event: SPIE Sensing Technology + Applications, 2015, Baltimore, MD, United SPIE. States 


\section{PROCEEDINGS OF SPIE}

\section{Quantum Information and Computation XIII}

Eric Donkor

Andrew R. Pirich

Michael Hayduk

Editors

22-24 April 2015

Baltimore, Maryland, United States

Sponsored and Published by

SPIE 
The papers included in this volume were part of the technical conference cited on the cover and title page. Papers were selected and subject to review by the editors and conference program committee. Some conference presentations may not be available for publication. The papers published in these proceedings reflect the work and thoughts of the authors and are published herein as submitted. The publisher is not responsible for the validity of the information or for any outcomes resulting from reliance thereon.

Please use the following format to cite material from this book:

Author(s), "Title of Paper," in Quantum Information and Computation XIII, edited by Eric Donkor, Andrew R. Pirich, Michael Hayduk, Proceedings of SPIE Vol. 9500 (SPIE, Bellingham, WA, 2015) Article CID Number.

ISSN: 0277-786X

ISBN: 9781628416169

Published by

SPIE

P.O. Box 10, Bellingham, Washington 98227-0010 USA

Telephone +1 3606763290 (Pacific Time) · Fax +1 3606471445

SPIE.org

Copyright (@ 2015, Society of Photo-Optical Instrumentation Engineers.

Copying of material in this book for internal or personal use, or for the internal or personal use of specific clients, beyond the fair use provisions granted by the U.S. Copyright Law is authorized by SPIE subject to payment of copying fees. The Transactional Reporting Service base fee for this volume is $\$ 18.00$ per article (or portion thereof), which should be paid directly to the Copyright Clearance Center (CCC), 222 Rosewood Drive, Danvers, MA 01923. Payment may also be made electronically through CCC Online at copyright.com. Other copying for republication, resale, advertising or promotion, or any form of systematic or multiple reproduction of any material in this book is prohibited except with permission in writing from the publisher. The CCC fee code is 0277-786X/15/\$18.00.

Printed in the United States of America.

Publication of record for individual papers is online in the SPIE Digital Library.

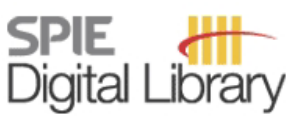

SPIEDigitalLibrary.org

Paper Numbering: Proceedings of SPIE follow an e-First publication model, with papers published first online and then in print. Papers are published as they are submitted and meet publication criteria. A unique citation identifier (CID) number is assigned to each article at the time of the first publication. Utilization of CIDs allows articles to be fully citable as soon as they are published online, and connects the same identifier to all online, print, and electronic versions of the publication. SPIE uses a six-digit CID article numbering system in which:

- The first four digits correspond to the SPIE volume number.

- The last two digits indicate publication order within the volume using a Base 36 numbering

system employing both numerals and letters. These two-number sets start with 00, 01, 02, 03, 04, $05,06,07,08,09,0 A, 0 B \ldots$. 0Z, followed by 10-1Z, 20-2Z, etc.

The CID Number appears on each page of the manuscript. The complete citation is used on the first page, and an abbreviated version on subsequent pages. 


\title{
Contents
}

\author{
vii Authors \\ ix Conference Committee
}

\section{SESSION 1 QKD AND QUANTUM CRYPTOGRAPHY}

950003 Performance limits for single-photons, correlated-photons, and entangled photons for quantum key distribution over fiber optics network topologies [9500-2]

950004 A continuous-variable quantum key distribution using correlated photons [9500-3]

950005 Quantum teleportation for keyless cryptography [9500-4]

950006 Implementing Diffie-Hellman key exchange using quantum EPR pairs [9500-5]

950007 Provably secure time distribution for the electric grid [9500-6]

950008 Secret key generation via a modified quantum secret sharing protocol [9500-7]

950009 Analysis of the secrecy of the running key in quantum encryption channels using coherent states of light [9500-8]

\section{SESSION 2 QUANTUM IMAGING AND SENSING}

9500 OD Complementary imaging with compressive sensing [9500-12]

$9500 \mathrm{OE}$ Sensors based on quantum hyper-entanglement: efficiency and performance in the presence of other photon sources [9500-13]

$9500 \mathrm{OF}$ Finding analytical solution for mirror inverse gate operations in quantum systems with diagonal interactions [9500-14]

\section{SESSION 3 QUANTUM GATES, CIRCUITS, AND NETWORKS I}

9500 0J Towards scalable quantum information processing with cold atoms and Rydberg blockade [9500-18]

9500 OK Scalable quantum computing architecture with mixed species ion chains [9500-19]

SESSION 4 QUANTUM GATES, CIRCUITS AND NETWORKS II

$95000 \mathrm{M}$ Superconducting metamaterials and qubits [9500-21] 
9500 OP Induced dipole-dipole forbidden transitions in rare-earth elements and their prospects for quantum information processing [9500-24]

\section{SESSION 5 QUANTUM MEASUREMENTS AND ERROR CORRECTION}

$95000 Q \quad$ How often must we apply syndrome measurements? [9500-25]

9500 OT Demonstrating continuous-variable Einstein-Podolsky-Rosen steering with a finite number of measurements [9500-28]

9500 OU Considerations on collapse of the wavefunction [9500-29]

SESSION 6 QUANTUM INFORMATION SCIENCE

9500 OV Staged quantum energy teleportation [9500-59]

9500 0W Diagrammatic quantum mechanics [9500-31]

9500 0X Principal fiber bundle description of number scaling for scalars and vectors: application to gauge theory [9500-32]

9500 OY Clocking in the face of unpredictability beyond quantum uncertainty [9500-33]

$95000 Z$ Topological and geometrical quantum computation in cohesive Khovanov homotopy type theory [9500-34]

$950010 \quad$ Heterotic quantum and classical computing on convergence spaces [9500-35]

950011 Quantum probabilistic logic programming [9500-36]

950012 Theoretical analysis of on-chip linear quantum optical information processing networks [9500-37]

\section{SESSION 7 QUANTUM STATES AND QUANTUM ENTANGLEMENT I}

950014 A bright PPKTP waveguide source of polarization entangled photons [9500-39]

950015 High spectral purity silicon ring resonator photon-pair source [9500-40]

950016 High heralding-efficiency of near-IR fiber coupled photon pairs for quantum technologies [9500-41]

950018 High-purity single-mode photon source for integrated quantum photonics [9500-43]

SESSION 8 QUANTUM STATES AND QUANTUM ENTANGLEMENT II

9500 1D Superconducting circuitry for quantum electromechanical systems [9500-48]

iv 
$95001 \mathrm{E} \quad$ Analog quantum computing (AQC) by revisiting the underlying physics [9500-53]

9500 IF A CNOT gate in a glass chip [9500-54]

9500 IG Characterizing a four-qubit planar lattice for arbitrary error detection [9500-55]

INTERACTIVE POSTER SESSION

$9500 \mathrm{1H}$ A novel quantum random number generation algorithm used by smartphone camera [9500-49]

9500 1J Calculation of key reduction for B92 QKD protocol [9500-52] 
Proc. of SPIE Vol. $9500950001-6$

Downloaded From: https://www.spiedigitallibrary.org/conference-proceedings-of-spie on 25 Apr 2023 Terms of Use: https://www.spiedigitallibrary.org/terms-of-use 


\section{Authors}

Numbers in the index correspond to the last two digits of the six-digit citation identifier (CID) article numbering system used in Proceedings of SPIE. The first four digits reflect the volume number. Base 36 numbering is employed for the last two digits and indicates the order of articles within the volume. Numbers start with 00, 01, 02, 03, 04, 05, 06, 07, 08, 09, OA, OB...0Z, followed by 10-1Z, 20-2Z, etc.

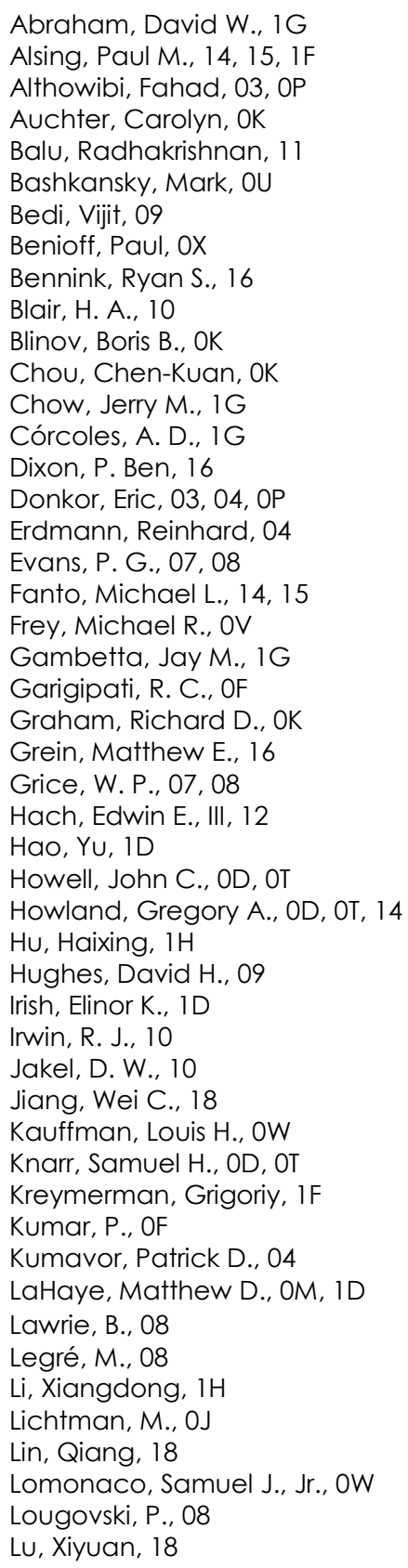

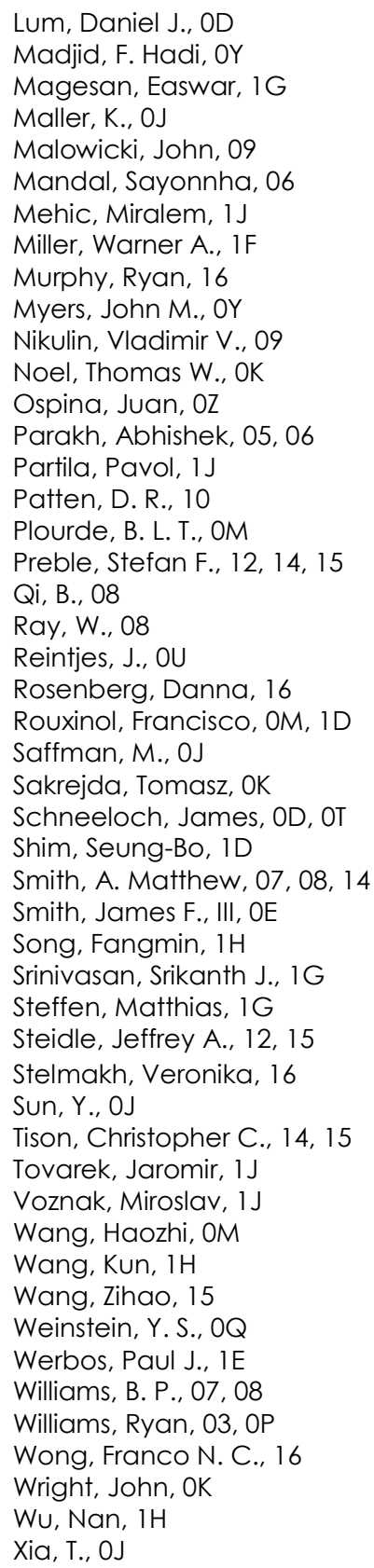


Zhang, Jidong, 18

Zhou, Zichao, OK

Proc. of SPIE Vol. $9500950001-8$

Downloaded From: https://www.spiedigitallibrary.org/conference-proceedings-of-spie on 25 Apr 2023 Terms of Use: https://www.spiedigitallibrary.org/terms-of-use 


\title{
Conference Committee
}

\author{
Symposium Chair
}

Wolfgang Schade, Clausthal University of Technology and Fraunhofer Heinrich-Hertz Institute (Germany)

Symposium Co-chair

Ming C. Wu, University of California, Berkeley (United States)

Conference Chairs

Eric Donkor, University of Connecticut (United States)

Andrew R. Pirich, ACP Consulting (United States)

Michael Hayduk, Air Force Research Laboratory (United States)

Conference Co-chairs

Michael R. Frey, Bucknell University (United States)

Samuel J. Lomonaco Jr., University of Maryland, Baltimore County (United States)

John M. Myers, Harvard University (United States)

Conference Program Committee

Paul M. Alsing, Air Force Research Laboratory (United States)

Chip Brig Elliott, Raytheon BBN Technologies (United States)

Reinhard K. Erdmann, Advanced Automation Corporation (United States)

Michael L. Fanto, Air Force Research Laboratory (United States)

Louis H. Kauffman, University of Illinois at Chicago (United States)

Vladimir E. Korepin, Stony Brook University (United States)

Alexander V. Sergienko, Boston University (United States)

Tai Tsun Wu, Harvard University (United States)

Session Chairs

1 QKD and Quantum Cryptography

Michael J. Hayduk, Air Force Research Laboratory (United States)

Michael L. Fanto, Air Force Research Laboratory (United States) 
2 Quantum Imaging and Sensing

Samuel J. Lomonaco Jr., University of Maryland, Baltimore County (United States)

Reinhard Erdmann, Advanced Automation Corporation

(United States)

3 Quantum Gates, Circuits, and Networks I

Eric Donkor, University of Connecticut (United States)

Samuel J. Lomonaco Jr., University of Maryland, Baltimore County (United States)

4 Quantum Gates, Circuits and Networks II

Reinhard Erdmann, Advanced Automation Corporation

(United States)

John M. Myers, Harvard University (United States)

5 Quantum Measurements and Error Correction

Michael R. Frey, Bucknell University (United States)

Louis H. Kauffman, University of Illinois at Chicago (United States)

6 Quantum Information Science

Michael L. Fanto, Air Force Research Laboratory (United States)

7 Quantum States and Quantum Entanglement I

John M. Myers, Harvard University (United States)

8 Quantum States and Quantum Entanglement II

Louis H. Kauffman, University of Illinois at Chicago (United States)

Michael R. Frey, Bucknell University (United States) 